\title{
Determinants and Prognostic Significance of the Renal Resistive Index
}

\author{
Nicholas Cauwenberghs Tatiana Kuznetsova \\ Research Unit Hypertension and Cardiovascular Epidemiology, KU Leuven Department of \\ Cardiovascular Sciences, University of Leuven, Leuven, Belgium
}

\section{Key Words}

Renal resistive index $\cdot$ Pulsatility $\cdot$ Renal target organ damage

\begin{abstract}
Background: The noninvasive assessment of renal hemodynamics is currently possible by assessing the renal resistive index (RRI) derived from intrarenal Doppler arterial waveforms as (peak systolic velocity - end-diastolic velocity)/peak systolic velocity. In this review, we outline the important determinants of the RRI to clarify the true identity of the RRI and highlight its potential diagnostic and prognostic value in renal and cardiovascular pathology. Summary: Although the RRI was initially considered to reflect intrarenal vascular pathological processes, this index is actually a product of a complex interaction between renal and systemic vascular wall properties and hemodynamic factors. Indeed, studies in patients and general populations consistently demonstrated a significant and direct association between the RRI and central or peripheral pulse pressure independent of other covariables. Moreover, studies in renal transplant patients also showed that the RRI mainly reflects characteristics of the recipient but not those of the graft. Thus, the major influence of the systemic hemodynamics on the intrarenal arterial waveforms excludes RRI as a specific marker of renal vascular pathology. On the other hand, because the RRI reflects pulsatility in renal arteries, it might be useful for the early detection of renal microvascular damage. Future longitudinal studies are still needed to clarify whether the detection of Doppler changes in intrarenal arteries might yield an improvement in the adverse cardiovascular and renal outcome. Conclusion: Published studies on RRI imply that the interaction between the systemic hemodynamics and peripheral circulation in the kidney is a complex physiological phenomenon. In addition to renal vascular properties, the central hemodynamic factors significantly influence the intrarenal arterial Doppler waveform patterns. Previous research also suggested an important role of the RRI for the evaluation of renal target organ damage, particularly in patients with increased pulsatility of the intrarenal blood flow.


Cauwenberghs and Kuznetsova: Determinants and Prognostic Significance of the Renal Resistive Index

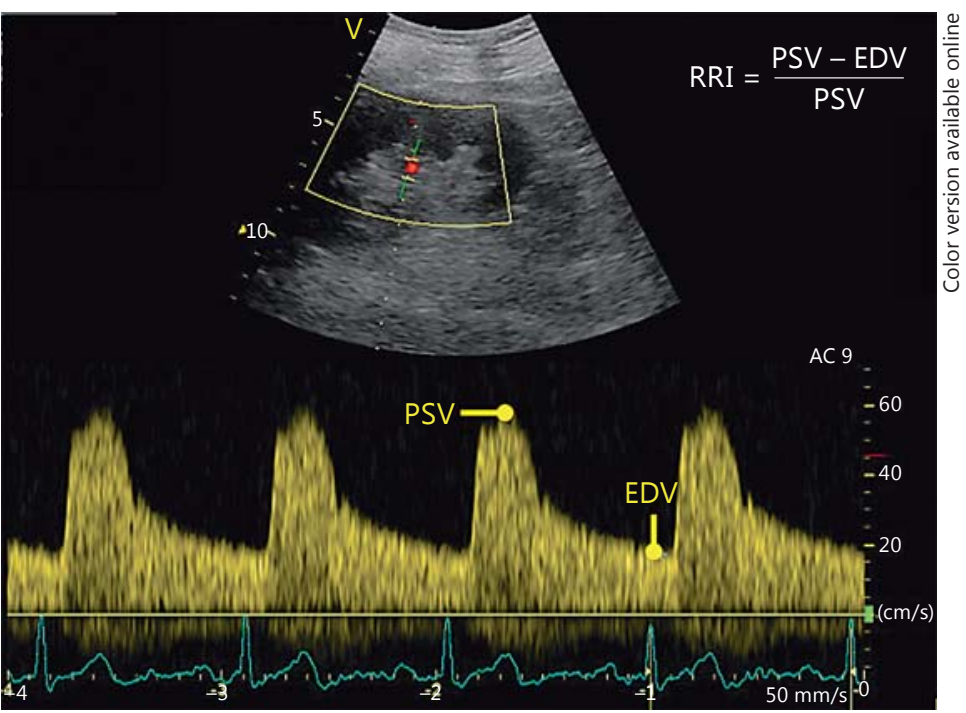

Fig. 1. Assessment of the RRI using Doppler ultrasonography. The RRI is derived from the intrarenal Doppler flow waveforms as (PSV-EDV)/PSV. PSV = Peak systolic velocity; $\mathrm{EDV}=$ end-diastolic velocity.

\section{Background}

The noninvasive assessment of renal hemodynamics is currently possible by analyzing the intrarenal arterial waveforms obtained by Doppler ultrasonography. The renal resistive index (RRI), derived from the Doppler flow-velocity waveform as (peak systolic velocity end-diastolic velocity)/peak systolic velocity, is the most described measure in renal Doppler ultrasonography (fig. 1) [1]. Over the last years, the RRI has been studied intensively to gain diagnostic and prognostic insights into a variety of renal clinical conditions such as assessment of renal allograft rejection [2,3], detection and management of renal artery stenosis in hypertensive patients $[4,5]$, evaluation of progression in chronic kidney disease [6] and prediction of renal and composite adverse outcomes in critically ill patients [7, 8]. Although the RRI was initially considered to reflect only intrarenal vascular pathological processes, this index is actually a product of a complex interaction between renal and systemic vascular wall properties and hemodynamic factors, yet most of these factors are insufficiently understood [1]. In this review, we outline the known hemodynamic and other determinants of the RRI to clarify the true identity of the RRI and highlight its potential diagnostic and prognostic value in renal and cardiovascular pathology.

When the RRI was introduced in the 1950s, its name was based on an assumption that this Doppler-derived index would largely reflect the vascular resistance of renal arteries. Over the last years, however, this initial belief has gradually been refuted. Indeed, theoretical analyses and experiments in artificial circuits demonstrated that the complex interaction between arterial resistance and compliance could alter the Doppler arterial waveform $[9,10]$. In fact, the higher the arterial compliance, the more the RRI was affected by arterial resistance and vice versa [10]. In experimental studies in isolated rabbit kidneys [11,12], an impaired renal vascular compliance and increased pulse pressure led to a significant increase in RRI. On the other hand, the RRI decreased with higher renal vascular resistance in transplanted kidneys [13]. Overall, these findings suggest that the RRI is a product of a complex interaction between a number of factors such as renal interstitial pressure, peripheral vascular resistance as well as compliance and systemic hemodynamics [1].

In experimental and clinical studies, the RRI was initially investigated in the setting of urinary obstruction [14], renal vein thrombosis [15] and acute renal inflammation [16]. For instance, in an ex vivo rabbit kidney model [11], hydronephrosis caused an increase in RRI. 
Cauwenberghs and Kuznetsova: Determinants and Prognostic Significance of the Rena Resistive Index

Table 1. Anthropometric and hemodynamic determinants of the RRI identified in patient and population studies

\begin{tabular}{|c|c|c|c|c|c|}
\hline $\begin{array}{l}\text { First author } \\
\text { [Ref.], year }\end{array}$ & Study population & Age, years & RRI & $\begin{array}{l}\text { Anthropometric } \\
\text { determinants of RRI }\end{array}$ & $\begin{array}{l}\text { Hemodynamic } \\
\text { determinants of RRI }\end{array}$ \\
\hline $\begin{array}{l}\text { Krumme [32], } \\
1997\end{array}$ & $\begin{array}{l}\text { Renal transplant } \\
\text { patients }(n=110)\end{array}$ & $45 \pm 13$ & $0.70 \pm 0.07$ & $\uparrow$ with age recipient & $\uparrow$ with $\mathrm{pPP}_{\text {recipient }}$ \\
\hline $\begin{array}{l}\text { Heine [33], } \\
2005\end{array}$ & $\begin{array}{l}\text { Renal transplant } \\
\text { patients }(\mathrm{n}=105)\end{array}$ & $53 \pm 14$ & $0.72 \pm 0.07$ & $\begin{array}{l}\uparrow \text { with age } \text { recipient }{ }{ }_{\text {recipient }} \\
\downarrow \text { with } \text { BMI }_{\text {recipient }}\end{array}$ & \\
\hline $\begin{array}{l}\text { Naesens [3], } \\
2013\end{array}$ & $\begin{array}{l}\text { Renal transplant } \\
\text { patients }(\mathrm{n}=321)\end{array}$ & $54 \pm 15$ & $0.74 \pm 0.08$ & $\uparrow$ with age recipient & $\begin{array}{l}\uparrow \text { with pPP } \\
\downarrow \text { recipient } \beta \text {-blockers } \\
\downarrow \text { with MAP }\end{array}$ \\
\hline $\begin{array}{l}\text { Ikee [34], } \\
2005\end{array}$ & $\begin{array}{l}\text { CKD patients } \\
(\mathrm{n}=33)\end{array}$ & $44 \pm 16$ & $0.56 \pm 0.06$ & $\uparrow$ with age & \\
\hline $\begin{array}{l}\text { Tedesco [25], } \\
2007\end{array}$ & $\begin{array}{l}\text { Hypertensive } \\
\text { patients }(n=566)\end{array}$ & $55 \pm 11$ & $0.68 \pm 0.05$ & $\uparrow$ with age & $\uparrow$ with pPP \\
\hline $\begin{array}{l}\text { Hashimoto [21], } \\
2011\end{array}$ & $\begin{array}{l}\text { Hypertensive } \\
\text { patients }(n=133)\end{array}$ & $56 \pm 12$ & $0.65 \pm 0.07$ & $\begin{array}{l}\uparrow \text { with age } \\
\downarrow \text { with body height }\end{array}$ & $\begin{array}{l}\uparrow \text { with cPP } \\
\downarrow \text { with MAP, HR }\end{array}$ \\
\hline $\begin{array}{l}\text { Stea [24], } \\
2013\end{array}$ & $\begin{array}{l}\text { Hypertensive } \\
\text { patients }(\mathrm{n}=216)\end{array}$ & $53 \pm 12$ & $0.63 \pm 0.07$ & $\uparrow$ with age, BMI & $\begin{array}{l}\uparrow \text { with cPP } \\
\downarrow \text { with DBP }\end{array}$ \\
\hline $\begin{array}{l}\text { Ponte [18], } \\
2014\end{array}$ & $\begin{array}{l}\text { General population } \\
(n=726)\end{array}$ & $\begin{array}{l}42 \pm 17\left(\sigma^{7}\right) \\
45 \pm 17(\%)\end{array}$ & $\begin{array}{l}0.62 \pm 0.05\left(\sigma^{7}\right) \\
0.64 \pm 0.05(q)\end{array}$ & $\uparrow$ with age,, , BMI & $\begin{array}{l}\uparrow \text { with pPP } \\
\downarrow \text { with DBP, HR }\end{array}$ \\
\hline $\begin{array}{l}\text { Kuznetsova [19], } \\
2015\end{array}$ & $\begin{array}{l}\text { General population } \\
(\mathrm{n}=171)\end{array}$ & $\begin{array}{l}53 \pm 14\left(\sigma^{7}\right) \\
52 \pm 14(\%)\end{array}$ & $\begin{array}{l}0.59 \pm 0.06\left(\sigma^{7}\right) \\
0.61 \pm 0.06(\%)\end{array}$ & $\begin{array}{l}\uparrow \text { with age, }, \text {, body weight } \\
\downarrow \text { with body height }\end{array}$ & $\begin{array}{l}\uparrow \text { with pPP, cPP, } \beta \text {-blockers } \\
\downarrow \text { with MAP } \\
\uparrow \text { with systolic and early } \\
\text { diastolic cardiac blood flows }\end{array}$ \\
\hline $\begin{array}{l}\operatorname{Lin}[20] \\
2003\end{array}$ & $\begin{array}{l}\text { Selected healthy } \\
\text { subjects }(n=135)\end{array}$ & $37(17-68)$ & $0.59 \pm 0.04$ & $\uparrow$ with age & $\downarrow$ with DBP \\
\hline
\end{tabular}

Age and RRI are indicated as mean \pm SD or median (range). $\mathrm{CKD}=$ Chronic kidney disease; $\mathrm{BMI}=$ body mass index; $\mathrm{pPP}=$ peripheral pulse pressure; $\mathrm{cPP}=$ central pulse pressure; $\mathrm{HR}=$ heart rate; $\mathrm{MAP}=$ mean arterial pressure; $\mathrm{DBP}=$ diastolic blood pressure.

In renal transplant patients [17], the RRI increased with increasing pressure applied by the ultrasound probe. Thus, the RRI might also be associated to some degree with pathological conditions affecting the renal interstitial and/or venous pressure [11].

\section{Relation of the RRI with Blood Pressure Components}

Systemic hemodynamics and peripheral arterial resistance and compliance have been demonstrated to affect the Doppler arterial waveform signal obtained in the intrarenal arteries. Peripheral arterial resistance is a main determinant of the steady component of blood pressure (or mean arterial pressure), and depends on the physical characteristics of the arterial tree. Studies in the general population $[18,19]$, in healthy subjects $[20]$ and in hypertensive patients [21] have reported an inverse relationship between the RRI and mean arterial pressure or diastolic blood pressure, independent of other covariables (table 1). These observations are in line with findings in transplanted kidneys, in which the RRI decreased significantly with higher renal vascular resistance [13].

On the other hand, compliance of the large arteries is a main determinant of the pulsatile component of blood pressure (or pulse pressure). During systole, the aortic and conduit arterial walls elastically expand to accommodate the ejected blood and, therefore, dampen 
Cauwenberghs and Kuznetsova: Determinants and Prognostic Significance of the Renal Resistive Index

pulsatility and guarantee a continuous blood flow from the heart to the periphery including the kidney. With aging, the rigidity is more pronounced in the aorta than in the peripheral conduit arteries including intrarenal arteries, leading to less protection of the microcirculation from high-pressure transmission in organs with high resting flow, such as the kidneys [22]. In fact, increased pulsatile stress leads to tearing of endothelial and smooth muscle cells of the small arteries in the kidney [23]. Therefore, a number of studies in patients and in the general population explored the association of the RRI with aortic (central) pulse pressure $[19,21,24]$ or peripheral (brachial) pulse pressure (table 1) $[18,19,25]$. All these studies [18, $19,21,24,25]$ consistently demonstrated a significant and direct association between the RRI and central or peripheral pulse pressure independent of other covariables.

\section{Relation of the RRI with Cardiac Blood Flows}

In addition to the blood pressure components reflecting vascular resistance and compliance, another important factor influencing the Doppler-derived RRI is the amount of renal blood flow [26]. The pivotal role of the kidney in the metabolic homeostasis makes it one of the peripheral territories with the highest perfusion. In fact, the $15-25 \%$ of the total cardiac output that the kidneys receive depends on the state of the body and the blood volume that the left ventricle ejects. Similarly to intrarenal blood flow, intracardiac blood flows can be quantified using Doppler echocardiography by quantification of blood velocities during systole and diastole [27]. Two studies in end-stage renal disease patients receiving hemodialysis $[28,29]$ demonstrated that changes in the total circulating volume (preload) significantly influence the Doppler blood flow velocity profiles in the left ventricle. Indeed, cardiac output and the left ventricular peak flow velocity during the early and late diastolic filling period decreased significantly after hemodialysis $[28,29]$. In a recent general population study in 171 subjects [19], we investigated the relationships between the RRI and indexes of left ventricular peak systolic and diastolic blood flow as measured at the left ventricular outflow tract and mitral valve. With adjustments applied, our study demonstrated in continuous analyses that the RRI significantly increased with higher systolic and early diastolic intracardiac Doppler blood flows. These findings imply that the exposure of small renal arteries to high blood flow in addition to high pulsatile pressure leads to an increased RRI and might in the long run result in microvascular damage and, therefore, renal insufficiency [23]. However, the cross-sectional design of this study does not allow a causal interpretation, and so far no population study has assessed longitudinal changes in cardiac and renal hemodynamics simultaneously. Therefore, the potential causal relationship between cardiac and renal hemodynamics still remains to be investigated.

Independent of the abovementioned factors, another hemodynamic factor, such as heart rate, might also affect the RRI by altering the duration of diastole. Indeed, one clinical study in 8 patients with a cardiac pacemaker [30], which allowed direct control of heart rate, has demonstrated the inverse relationship between the RRI and heart rate. Studies in the general population [18] as well as in hypertensive patients [21] have confirmed an inverse and independent relationship between heart rate and the RRI. Along these lines, in a general population [19] and in renal transplant patients [3], the RRI increased independently with the use of $\beta$-blockers (table 1 ).

In addition, several anthropometric factors have been reported as independent determinants of the RRI in hypertensive patients [21, 24, 25] and the general population $[18,19]$ (table 1). In the two general population studies $[18,19]$, the RRI was directly related to female sex, age and body weight and inversely related to body height in multivariable-adjusted analyses. 
Cauwenberghs and Kuznetsova: Determinants and Prognostic Significance of the Renal Resistive Index

\section{Prognostic Significance of the RRI}

The RRI has been studied and used widely to gain diagnostic and prognostic insights into a variety of renal clinical conditions such as renal allograft rejection $[2,3]$, renal artery stenosis in hypertensive patients [4,5], progression of chronic kidney disease [6] and renal and composite adverse outcomes in critically ill patients [7, 8].

Two studies in renal transplant patients investigated the prognostic value of the RRI on allograft rejection and overall survival of patients [3,31]. Such transplant studies also provided important information on the influence of the renovascular (graft-specific) determinants and the systemic (recipient-specific) determinants on the RRI. For instance, in renal transplant recipients $[3,32,33]$, the RRI correlated with the age of the recipient, but not with the donor's age. Furthermore, a study in 321 renal transplant patients [3] reported a correlation of the RRI with the recipient's peripheral pulse pressure and mean arterial pressure, suggesting that the RRI of the donor-specific intrarenal arteries is largely influenced by the systemic hemodynamics of the recipient. Moreover, a high RRI was associated with recipient survival but not with graft survival [3,31]. Overall, these findings demonstrated that, in renal transplant patients, the RRI mainly reflects characteristics of the recipient but not those of the graft.

Along these lines, Ikee et al. [34] demonstrated that, in 33 patients with a chronic renal disease, the RRI was not independently related to glomerular, tubular or interstitial renal histology and only arteriolosclerosis was found to be an independent factor associated with an increased RRI. Several previous studies demonstrated that a side-to-side difference in RRI of at least 0.05 is a specific marker of severe unilateral renal artery stenosis [35]. However, because of the major influence of the systemic hemodynamic factors and renal vascular compliance on the intrarenal arterial waveforms, the RRI could not serve as a specific marker reflecting exclusively renal artery resistance or renal pathology.

Although current knowledge seriously questions the clinical value of the RRI in renal diseases, its 'new' identity as an index of pulsatility in renal arteries might imply a new application potential of the RRI in aging and vascular pathology. Indeed, in the setting of an increased flow pulsation, the RRI might be a useful marker for the early detection of renal microvascular damage following altered systemic and/or renal hemodynamics. A recent study in 426 patients with essential hypertension [36] demonstrated that impairment of renal hemodynamics as assessed by an increased RRI was associated with an increased risk of cardiovascular and renal outcomes. In hypertensive patients, evaluation of RRI might be useful and complementary to other predictors of cardiovascular and renal outcomes [36]. To date, however, longitudinal studies are still needed to clarify whether (early) detection of Doppler changes in intrarenal arteries might yield an improvement in the adverse cardiovascular and renal outcome in the general population and hypertensive patients.

In conclusion, published studies on RRI imply that the interaction between the systemic hemodynamics and peripheral circulation in the kidney is a complex physiological phenomenon. In addition to renal vascular properties, anthropometric and central hemodynamic factors influence the intrarenal arterial Doppler waveform patterns. Previous research also suggests an important role for the RRI in the evaluation of renal target organ damage, particularly in patients with increased pulsatility of blood flow. Further longitudinal population studies are required to clarify whether early detection of Doppler changes in intrarenal arteries might yield an improvement in the adverse cardiovascular and renal outcome in the general population and in patients. 
Resistive Index

\section{Acknowledgments}

Nicholas Cauwenberghs is a recipient of the research grant of the Fonds voor Wetenschappelijk Onderzoek Vlaanderen (the FWO Flanders, grant 11Z0916N). The Research Unit Hypertension and Cardiovascular Epidemiology received grants from the FWO Flanders (grants G.0880.13 and G. 0881.13).

\section{Disclosure Statement}

The authors have no conflicts of interest to declare.

\section{References}

1 Tublin ME, Bude RO, Platt JF: The resistive index in renal Doppler sonography: where do we stand? AJR Am J Roentgenol 2003;180:885-892.

2 Radermacher J, Mengel M, Ellis S, Stuht S, Hiss M, Schwarz A, et al: The renal arterial resistance index and renal allograft survival. N Engl J Med 2003;349:115-124.

3 Naesens M, Heylen L, Lerut E, Claes K, De Wever L, Claus F, et al: Intrarenal resistive index after renal transplantation. N Engl J Med 2013;369:1797-1806.

4 Radermacher J, Chavan A, Bleck J, Vitzthum A, Stoess B, Gebel MJ, et al: Use of Doppler ultrasonography to predict the outcome of therapy for renal-artery stenosis. N Engl J Med 2001;344:410-417.

5 Crutchley TA, Pearce JD, Craven TE, Stafford JM, Edwards MS, Hansen KJ: Clinical utility of the resistive index in atherosclerotic renovascular disease. J Vasc Surg 2009;49:148-155.

6 Radermacher J, Ellis S, Haller H: Renal resistance index and progression of renal disease. Hypertension 2002; 29(2 Pt 2):699-703.

7 Le Dorze M, Bouglé A, Deruddre S, Duranteau J: Renal Doppler ultrasound: a new tool to assess renal perfusion in critical illness. Shock 2012;37:360-365.

8 Darmon M, Schortgen F, Vargas F, Liazydi A, Schlemmer B, Brun-Buisson C, et al: Diagnostic accuracy of Doppler renal resistive index for reversibility of acute kidney injury in critically ill patients. Intensive Care Med 2011;37:68-76.

9 Gosling RG, Lo PT, Taylor MG: Interpretation of pulsatility index in feeder arteries to low-impedance vascular beds. Ultrasound Obstet Gynecol 1991;1:175-179.

10 Bude RO, Rubin JM: Relationship between the resistive index and vascular compliance and resistance. Radiology 1999;211:411-417.

11 Murphy ME, Tublin ME: Understanding the Doppler RI: impact of renal arterial distensibility on the RI in a hydronephrotic ex vivo rabbit kidney model. J Ultrasound Med 2000;19:303-314.

12 Tublin ME, Tessler FN, Murphy ME: Correlation between renal vascular resistance, pulse pressure, and the resistive index in isolated perfused rabbit kidneys. Radiology 1999;213:258-264.

13 Bruno S, Ferrari S, Remuzzi G, Ruggenenti P: Doppler ultrasonography in posttransplant renal artery stenosis: a reliable tool for assessing effectiveness of revascularization? Transplantation 2003;76:147-153.

14 Gottlieb RH, Luhmann K, Oates RP: Duplex ultrasound evaluation of normal native kidneys and native kidneys with urinary tract obstruction. J Ultrasound Med 1989;8:609-611.

15 Platt JF, Ellis JH, Rubin JM: Intrarenal arterial Doppler sonography in the detection of renal vein thrombosis of the native kidney. AJR Am J Roentgenol 1994;162:1367-1370.

16 Platt JF, Ellis JH, Rubin JM, DiPietro MA, Sedman AB: Intrarenal arterial Doppler sonography in patients with nonobstructive renal disease: correlation of resistive index with biopsy findings. AJR Am J Roentgenol 1990; 154:1223-1227.

17 Pozniak MA, Kelcz F, Stratta RJ, Oberley TD: Extraneous factors affecting resistive index. Invest Radiol 1988; 23:899-904.

18 Ponte B, Pruijm M, Ackermann D, Vuistiner P, Eisenberger U, Guessous I, et al: Reference values and factors associated with renal resistive index in a family-based population study. Hypertension 2014;63:136-142.

19 Kuznetsova T, Cauwenberghs N, Knez J, Thijs L, Liu YP, Gu YM, et al: Doppler indexes of left ventricular systolic and diastolic flow and central pulse pressure in relation to renal resistive index. Am J Hypertens 2015;28: 535-545.

20 Lin ZY, Wang LY, Yu ML, Dai CY, Chen SC, Chuang WL, et al: Influence of age on intrarenel resistive index measurement in normal subjects. Abdom Imaging 2003;28:230-232.

21 Hashimoto J, Ito S: Central pulse pressure and aortic stiffness determine renal hemodynamics: pathophysiological implication for microalbuminuria in hypertension. Hypertension 2011;58:839-846.

22 Briet M, Boutouyrie P, Laurent S, London GM: Arterial stiffness and pulse pressure in CKD and ESRD. Kidney Int 2012;82:388-400. 
23 O'Rourke MF, Safar ME: Relationship between aortic stiffening and microvascular disease in brain and kidney: cause and logic of therapy. Hypertension 2005;46:200-204.

24 Stea F, Sgrò M, Faita F, Bruno RM, Cartoni G, Armenia S, et al: Relationship between wave reflection and renal damage in hypertensive patients: a retrospective analysis. J Hypertens 2013;31:2418-2424.

25 Tedesco MA, Natale F, Mocerino R, Tassinario G, Calabrò R: Renal resistive index and cardiovascular organ damage in a large population of hypertensive patients. J Hum Hypertens 2007;21:291-296.

26 Darmon M, Schnell D, Zeni F: Doppler-based renal resistive index: a comprehensive review; in Vincent J-L (ed): Yearbook of Intesive Care and Emergency Medicine. Springer, Heidelberg, 2010, pp 331-338.

27 Quiñones MA, Otto CM, Stoddard M, Waggoner A, Zoghbi WA; Doppler Quantification Task Force of the Nomenclature and Standards Committee of the American Society of Echocardiography: Recommendations for quantification of Doppler echocardiography: a report from the Doppler Quantification Task Force of the Nomenclature and Standards Committee of the American Society of Echocardiography. J Am Soc Echocardiogr 2002; 15:167-184.

28 Mendes L, Ribeiras R, Adragão T, Lima S, Horta E, Reis C, et al: Load-independent parameters of diastolic and systolic function by speckle tracking and tissue Doppler in hemodialysis patients. Rev Port Cardiol 2008;27: 1011-1025.

29 Hung KC, Huang HL, Chu CM, Yeh KH, Fang JT, Lin FC: Effects of altered volume loading on left ventricular hemodynamics and diastolic filling during hemodialysis. Ren Fail 2004;26:141-147.

30 Mostbeck GH, Gössinger HD, Mallek R, Siostrzonek P, Schneider B, Tscholakoff D: Effect of heart rate on Doppler measurements of resistive index in renal arteries. Radiology 1990;175:511-513.

31 Seiler S, Colbus SM, Lucisano G, Rogacev KS, Gerhart MK, Ziegler M, et al: Ultrasound renal resistive index is not an organ-specific predictor of allograft outcome. Nephrol Dial Transplant 2012;27:3315-3320.

32 Krumme B, Grotz W, Kirste G, Schollmeyer P, Rump LC: Determinants of intrarenal Doppler indices in stable renal allografts. J Am Soc Nephrol 1997;8:813-816.

33 Heine GH, Gerhart MK, Ulrich C, Köhler H, Girndt M: Renal Doppler resistance indices are associated with systemic atherosclerosis in kidney transplant recipients. Kidney Int 2005;68:878-885.

34 Ikee R, Kobayashi S, Hemmi N, Imakiire T, Kikuchi Y, Moriya H, et al: Correlation between the resistive index by Doppler ultrasound and kidney function and histology. Am J Kidney Dis 2005;46:603-609.

35 Zeller T: Renal artery stenosis: epidemiology, clinical manifestation, and percutaneous endovascular therapy. J Interv Cardiol 2005;18:497-506.

36 Doi Y, Iwashima Y, Yoshihara F, Kamide K, Hayashi S, Kubota Y, et al: Renal resistive index and cardiovascular and renal outcomes in essential hypertension. Hypertension 2012;60:770-777. 